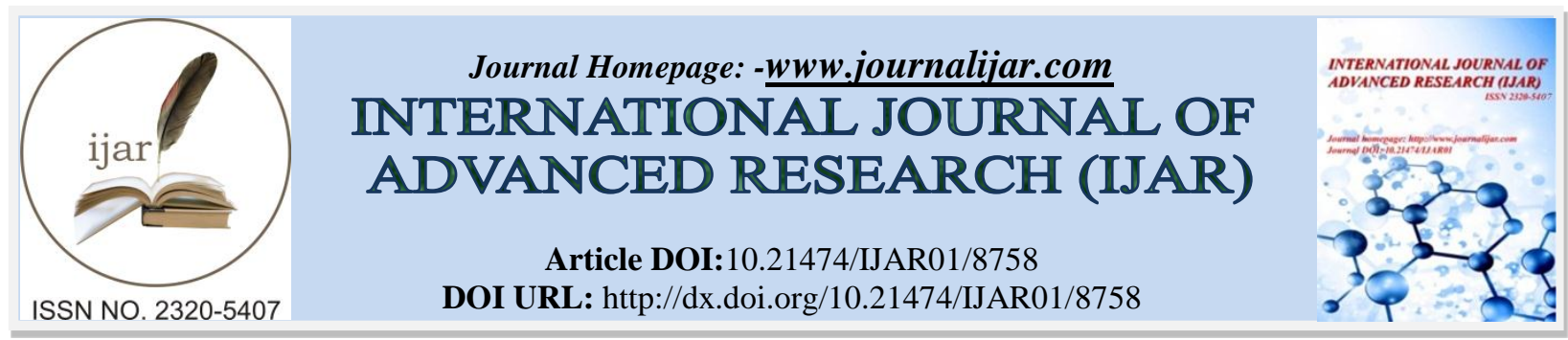

RESEARCH ARTICLE

\title{
A FACILE SYNTHESIS OF PALLADIUM CONTAINING METALLODENDRIMER BASED ON DIAZINE AND ITS APPLICATION AS A CATALYST.
}

Md. Sayedul Islam and Md. Wahab Khan.

Department of Chemistry, Faculty of Engineering, Bangladesh University of Engineering and Technology (BUET), Dhaka-1000, Bangladesh.

\section{Manuscript Info}

Manuscript History

Received: 20 January 2019

Final Accepted: 22 February 2019

Published: March 2019

Key words:-

Diazine, Aroyl chloride, phenylacetylene, Triaminopyrimidine, Metallodendrimer.

\section{Abstract}

A palladium containing metallodendrimer has been directly prepared by the reaction of 2,4,6-Triaminopyrimidine (Diazine) with 4-methyl benzoyl chloride using $\left(\mathrm{Ph}_{3} \mathrm{P}\right)_{2} \mathrm{PdCl}_{2}$ in $\mathrm{DMF}$ at $70{ }^{\circ} \mathrm{C}$ in good yields. The compound was characterized with IR, NMR, Mass and other spectroscopic methods while SEM and EDX showed the surface morphology and the presence of Palladium chloride of the compound. TG and DSC exhibited the good thermal stability of the metallodendrimer. The compound was found to be an effective homogeneous catalyst for the $\mathrm{C}-\mathrm{C}$ cross-coupling reaction such as Heck and Sonogashira.

Copy Right, IJAR, 2019,. All rights reserved.

\section{Introduction:-}

In the past two decades, the idea and synthesis of dendrimers have received increasing find out [1,2] not only since of the aesthetically pleasing structures of these molecules but also as an event of their various applications in hostguest chemistry [3], material science [4], and membrane chemistry [5]. So far, two complementary methodologies [6, 7], the divergent and the convergent were implemented within the preparation of dendrimers.

Metallodendrimers are the unique magnificence of synthetic macromolecules having remarkably branched, three dimensional, nanoscale design with very low polydispersity and excessive functionality [8]. Active centre in a metallodendrimer may be situated in three extraordinary areas: (i) metallic atom as the dendrimer center, (ii) metal atoms within the dendrimer branches (iii) metallic atoms in the outer edge. Such as PAMAM dendrimers can coordinate different transition metals through their nitrogen atoms.

Metals able to coordinate with the PAMAM structure include among others $\mathrm{Cu}[9,10] \mathrm{Au}[11] \mathrm{Pd}[12] \mathrm{Pt}$ [13] $\mathrm{Ag}$ [14] $\mathrm{Co}[15]$ as well as bimetallic systems such as $\mathrm{Pd}-\mathrm{Au}[16]$ and $\mathrm{Pt}-\mathrm{Ru}[17]$.

Recently, metallodendrimers have been widely investigated in different fields, which includes molecular light harvesting, catalysts, liquid crystals, molecular encapsulation, and drug delivery [18]. The majority of the studies has been achieved in the field of catalysis where metals such as $\mathrm{Cu}$ (II), $\mathrm{Rh}$ (III), $\mathrm{Ru}$ (II), Pd (II), Fe (I) and Co (III) are used in the production of metallodendrimers. In addition to, metallodendrimer compounds have been prepared via click chemistry, employing Diels-Alder reactions [19], thiolene reactions [20], and azide-alkyne reactions [21, 22]. Here we report the synthesis and characterization of a new class of homogeneous Pd containing diazine-

Corresponding Author:-Md. Sayedul Islam.

Address:-Department of Chemistry, Faculty of Engineering, Bangladesh University of Engineering and Technology (BUET), Dhaka-1000, Bangladesh. 
based metallodendrimer which have shown efficient catalytic activity in the Heck and Sonogashira crosscoupling reaction.

\section{Experimental Section:}

Unless in any other case noted, all reagents were reagent grade and used without further purification. Dehydrated DMF, DMSO, $\mathrm{CH}_{3} \mathrm{CN}$ and THF were used as reaction solvent. Those solvents were bought from Aldrich and used as required. De-ionized water was used in the experiment in which required. The IR spectra was taken on a Shimadzu FTIR 8400S Fourier remodel Infrared Spectrophotometer (four hundred-4000 cm-1) with $\mathrm{KBr}$ pellets. ${ }^{1} \mathrm{H}$ NMR and ${ }^{13} \mathrm{C}$ NMR spectra were recorded at $300 \mathrm{MHz}$ and $75 \mathrm{MHz}$, respectively, on a JEOL AL 300/BZ tool as well as BRUKER DPX-400 MHz \& $100 \mathrm{MHz}$ spectrophotometer respectively. Chemical shifts was taken relative to TMS. Mass spectra (MS) was measured with the aid of the usage of AXIMA-CFR, Shimadzu/Kratos TOF Mass spectrometer. Scanning Electron Microscope (SEM) and power Dispersive X-ray (EDX) was taken on a Hitachi S4800. Analytical thin layer chromatography (TLC) became silica gel $60 \mathrm{~F} 254$ covered on 25 TCC aluminum sheets $(20 \times 20 \mathrm{~cm}) .2$, 4, 6-triamino-1, 3, 5-diazine, 4-methyl benzoyl chloride and $\left(\mathrm{Ph}_{3} \mathrm{P}\right)_{2} \mathrm{PdCl}_{2}$ were purchased from Sigma Aldrich and had been directly used without further purification. The thermal behavior of metallodendrimer was determined by a thermogravimetric analyzer (NETZSCH STA 449F3) from 26 to $600{ }^{\circ} \mathrm{C}$. Elemental analyses were carried out with a Fisons EA 1108 CHNS-O apparatus. All TG and DSC facts had been received under a nitrogen environment by the use of aluminum oxide crucible at a heating fee of $10{ }^{\circ} \mathrm{k} / \mathrm{min}$ and at a flow rate of 40 and $60 \mathrm{~mL} / \mathrm{min}$.

Synthesis of 2, 4, 6-Tris (di-4-methylbenzamido)-1, 3, 5-Diazine Palladium (II) chloride (3) 4-Methyl benzoyl chloride $2(1.47 \mathrm{~g}, 9.54 \mathrm{mmol}),\left(\mathrm{Ph}_{3} \mathrm{P}\right)_{2} \mathrm{PdCl}_{2}(0.11 \mathrm{~g}, 10 \% \mathrm{~mol})$ were sequentially added to a solution of 2, 4, 6-triamino-1, 3, 5-diazine $1(0.2 \mathrm{~g}, 1.59 \mathrm{mmol})$ in DMF $(10 \mathrm{~mL})$. The solution was degassed and stirred at room temperature under a nitrogen atmosphere for $1 \mathrm{~h}$ and the reaction was continued for $5 \mathrm{~h}$ at $70{ }^{\circ} \mathrm{C}$. The progress of the reaction was monitored by TLC. At the starting of the reaction, the mixture was turned into a clear solution and graduallyit turned into white solid. After completion of the reaction, distilled $\mathrm{H}_{2} \mathrm{O}$ was added. After the removal of solvent, the product was washed with sodium hydrogen carbonate solution and purified by recrystallization by using ethanol and found the desired product 3 .

White crystalline solid; yield: $90 \%$.; IR (KBr): $v_{\max } 3052.29,2976.31,1710.20,1611.69,1418.69,1360.20 \mathrm{~cm}^{-1}{ }^{1} \mathrm{H}$ NMR (300 MHz, CD $\left.{ }_{3} \mathrm{OD}\right): \delta 7.80(\mathrm{~m}, 12 \mathrm{H}), 7.23(\mathrm{~m}, 12 \mathrm{H}), 4.96(\mathrm{~s}, 1 \mathrm{H}) 2.3(\mathrm{~s}, 18 \mathrm{H}) \mathrm{ppm} .{ }^{13} \mathrm{C} \mathrm{NMR}(75 \mathrm{MHz}$, $\mathrm{CDCl} 3): \delta$ 21.63, 129.28, 130.50, 131.28, 144.63 and $172.33 \mathrm{ppm}$. MALDI-TOF MS: $\mathrm{m} / \mathrm{z}(\%)=$ calcd. for $\mathrm{C}_{52} \mathrm{~N}_{5} \mathrm{H}_{43} \mathrm{O}_{6} \mathrm{Pd}_{3} \mathrm{Cl}_{6}$ 1365.90; found 1369.44 (100) [M] ${ }^{+}$, Anal. Calcd. (\%) for $\mathrm{C}_{52} \mathrm{~N}_{5} \mathrm{H}_{43} \mathrm{O}_{6} \mathrm{Pd}_{3} \mathrm{Cl}_{6}$ : C, 45.70; H, 3.17; N, 5.13. Found: C, 45.67; H, 3.10; N, 5.10.

Application of Pd-metallodendrimer 3 as a catalyst in the Sonogasira reaction:

Synthesis of 4-(2-phenylethynyl)phenol 14, [30]

4-Iodophenol (1 mmol), Pd-metallodendrimer 3 (1.5 mol\%), CuI $0.5 \mathrm{~mol} \%$ were kept in a R.B flask with phenylacetylene $(1.2 \mathrm{mmol})$ under the nitrogen atmosphere and $\mathrm{Et}_{3} \mathrm{~N}(2 \mathrm{~mL})$ as a base and $\mathrm{CH}_{3} \mathrm{CN}(5 \mathrm{~mL})$ as a solvent were added into the reaction flask. The resulting mixture was stirred at $60{ }^{\circ} \mathrm{C}$ temperatures for $3 \mathrm{hrs}$ and the reaction was checked by TLC. Then the solvent was vaporized under reduced pressure and the residue obtained was purified by silica gel chromatography using ethyl acetate and hexane (4:1) and solid product was obtained, mp: 124$126{ }^{\circ} \mathrm{C} ;{ }^{1} \mathrm{H}-\mathrm{NMR}\left(\mathrm{CDCl}_{3}, 400 \mathrm{MHz}\right): \delta 5.08(\mathrm{~s}, 1 \mathrm{H}, \mathrm{OH}) ; 6.75(\mathrm{~d}, 2 \mathrm{H}, J=8.8 \mathrm{~Hz}) ; 7.29-7.35(\mathrm{~m}, 3 \mathrm{H}) ; 7.43(\mathrm{~d}, J=$ $8.8,2 \mathrm{H}) ; 7.55(\mathrm{~d}, J=8.8,2 \mathrm{H}) .{ }^{13} \mathrm{C}$ NMR $\left(100 \mathrm{MHz}, \mathrm{CDCl}_{3}\right): \delta 93.93,114.13,115.30,123.97,128.47,129.03$, $133.93,134.43,159.51$.

Synthesis of 1-(2-p-tolylethynyl)benzene, 15 [30]

Solid colourless product was obtained, mp: $70-72{ }^{\circ} \mathrm{C}$ (lit. $\left.71{ }^{\circ} \mathrm{C}\right) ;{ }^{1} \mathrm{H}$ NMR $(400 \mathrm{MHz}): \delta 2.31(\mathrm{~s}, 3 \mathrm{H}) ; 7.20(\mathrm{~d}, 2 \mathrm{H}$, $J=8.8 \mathrm{~Hz}) ; 7.32(\mathrm{t}, 3 \mathrm{H}, J=5.6 \mathrm{~Hz}) ; 7.33(\mathrm{~d}, 2 \mathrm{H}, J=8.4 \mathrm{~Hz}) ; 7.54(\mathrm{~d}, 2 \mathrm{H}, J=8.0 \mathrm{~Hz}) .{ }^{13} \mathrm{C} N \mathrm{NR}(100 \mathrm{MHz}$, $\left.\mathrm{CDCl}_{3}\right): \delta 92.51,93.13,120.20,122.23,128.27,128.47,128.97,132.03,133.93,139.13$.

Synthesis of 1-(2-(4-methoxyphenyl)ethynyl)benzene, 16 [31]

Solid white product was obtained, mp: $54-56{ }^{\circ} \mathrm{C}$ (lit. $\left.57{ }^{\circ} \mathrm{C}\right) ;{ }^{1} \mathrm{H}$ NMR $(400 \mathrm{MHz}): \delta 3.71(\mathrm{~s}, 3 \mathrm{H}) ; 6.88(\mathrm{~d}, 2 \mathrm{H}$, $J=8.8 \mathrm{~Hz}) ; 7.33$ (t, $J=10.8,3 \mathrm{H}) ; 7.36(\mathrm{~d}, 2 \mathrm{H}, J=8.8 \mathrm{~Hz}) ; 7.44$ (d, $2 \mathrm{H}, J=8.0)$. 
C NMR (100 MHz, $\left.\mathrm{CDCl}_{3}\right): \delta 55.51,93.23,113.23,115.20,123.37,128.47,129.47,132.03,133.93,160.97$.

Application of Pd-metallodendrimer 3 as a catalyst in the Heck reaction.

A combination of 4-Iodophenol (1 mmol) with styrene (1.2 mmol), Pd-metallodendrimer 3 (1.5 mol\%) and triethylamine $(1.2 \mathrm{~mL})$ was stirred in DMF $(5 \mathrm{~mL})$ in an R.B flask under nitrogen environment. The solution was heated at $85{ }^{\circ} \mathrm{C}$ for $24 \mathrm{hrs}$. The advancement of the reaction was observed with the aid of TLC (n-hexane/ethyl acetate 1:1). After the achievement of the desired conversion of the reaction, the reaction mixture was evaporated to dryness under reduced pressure and the residue was turned into extracted with chloroform. The chloroform extract was washed with distilled water and dried over anhydrous $\mathrm{Na}_{2} \mathrm{SO}_{4}$, filtered and concentrated under reduced pressure. Then it was refined by silica gel column chromatography with n-hexane / ethyl acetate (3:1). Solid colourless trans stilbene, 22 [32] was found and melting point was $74-76{ }^{\circ} \mathrm{C}, \mathrm{IR}(\mathrm{KBr}): v_{\max } 3027,1600.35,1496,1452.24,1319.36$, 1267.27, 962.35, 909.25, 733.74. ${ }^{1} \mathrm{H}$ NMR (400 MHz, $\mathrm{CDCl}_{3}$ ), $\delta 7.02$ (s, $\left.2 \mathrm{H}\right), 7.35$ (dd, $1 \mathrm{H}, \mathrm{J}=1.2 \mathrm{~Hz}, 7.2 \mathrm{~Hz}$ ), $7.43(\mathrm{dd}, 4 \mathrm{H}, J=9.2 \mathrm{~Hz}, 7.2 \mathrm{~Hz}), 7.63(\mathrm{dd}, 4 \mathrm{H}, J=1.2 \mathrm{~Hz}, 8.8 \mathrm{~Hz}) .{ }^{13} \mathrm{C}$ NMR $\left(100 \mathrm{MHz}, \mathrm{CDCl}_{3}\right): \delta 126.56,127.61$, $128.11,128.85,137.46$.

(E)-Methyl 3-o-tolylacrylate, 23 [32]

IR (KBr): $v_{\max } 2950.32,1722.32,1639.35,1267.27,1220.20,1172.21,980.30,764.27 .{ }^{1} \mathrm{H} \mathrm{NMR}\left(400 \mathrm{MHz}, \mathrm{CDCl}_{3}\right)$,

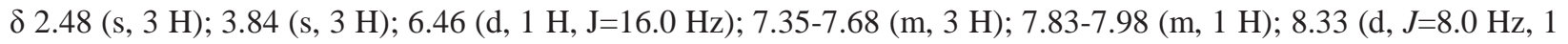
$\mathrm{H})$.

${ }^{13} \mathrm{C}$ NMR $\left(100 \mathrm{MHz}, \mathrm{CDCl}_{3}\right): \delta 19.66,51.56,118.46,126.17,126.61,130.11,130.75,133.56,137.66,142.46$, 167.36 .

Methoxy-4-styrylbenzene, 24 [32]

mp. $135-137{ }^{\circ} \mathrm{C}$, IR (KBr): $v_{\max } 2960.74,1601.35,1511.24,1319.35,1251.27,1179.75,1031.15,966.36,812.25 .{ }^{1} \mathrm{H}$ NMR (400 MHz, $\left.\mathrm{CDCl}_{3}\right), \delta 3.88(\mathrm{~s}, 3 \mathrm{H}) ; 6.37(\mathrm{~d}, 2 \mathrm{H}, J=8.0 \mathrm{~Hz}) ; 6.57(\mathrm{~d}, 1 \mathrm{H}, J=16 \mathrm{~Hz}) ; 6.86$ (d, $\left.1 \mathrm{H}, J=16 \mathrm{~Hz}\right)$; 6.39-6.29 (m, $1 \mathrm{H}) ; 7.58(\mathrm{t}, 2 \mathrm{H}, J=7.2 \mathrm{~Hz}) ; 7.94(\mathrm{t}, 4 \mathrm{H}, J=9.2 \mathrm{~Hz}) .{ }^{13} \mathrm{C} \mathrm{NMR}\left(100 \mathrm{MHz}, \mathrm{CDCl}_{3}\right): \delta 55.31,114.29$, $126.32,126.76,127.26,127.86,128.33,128.77,130.22,137.34,159.40$.

\section{Results and Discussion:-}

Metallodendrimer (3) was synthesized by the reaction of 2,4,6-Triaminopyrimidine 1(1.59 mmol) with 4-methyl benzoyl chloride $2(9.54 \mathrm{mmol})$ in the presence of $\left(\mathrm{Ph}_{3} \mathrm{P}\right)_{2} \mathrm{PdCl}_{2}(10 \mathrm{~mol} \%)$ in anhydrous DMF at room temperature to $70{ }^{\circ} \mathrm{C}$ for $6 \mathrm{~h}$ under a nitrogen atmosphere (Scheme 1). The progress of reaction was monitored by thin layer chromatography (TLC) and after complete conversion of the reaction, purification of the solid reaction mixture by recrystallization gave the dendrimerized product 3 in $90 \%$ yield (Table 1, entry 1 ). $\mathrm{PdCl}_{2}$ was also effective and provided 3 in $60 \%$ (entry 2). Since $\left(\mathrm{Ph}_{3} \mathrm{P}\right)_{2} \mathrm{PdCl}_{2}$ was given more yield than $\mathrm{PdCl}_{2}$, we selected $\left(\mathrm{Ph}_{3} \mathrm{P}\right)_{2} \mathrm{PdCl}_{2}$ for the later optimization. The use of tetrahydrofuran as the solvent caused in low yields of $\mathbf{3}$, because of the poor solubility of 3 (entry 3). DMSO also good solvent and gave 3 in $85 \%$ (entry 4). Increasing the amount of $\left(\mathrm{Ph}_{3} \mathrm{P}\right)_{2} \mathrm{PdCl}_{2}$ from 10 to $20 \mathrm{~mol} \%$ did not progress the final yield of $\mathbf{3}$, the yield reduced due to the creation of a complex as a byproduct instead of the desired product (entry 5). The product was found to be soluble in all common organic solvents, and was characterized by IR, ${ }^{1} \mathrm{H}$ NMR, ${ }^{13} \mathrm{C}$ NMR, and mass spectrometry.

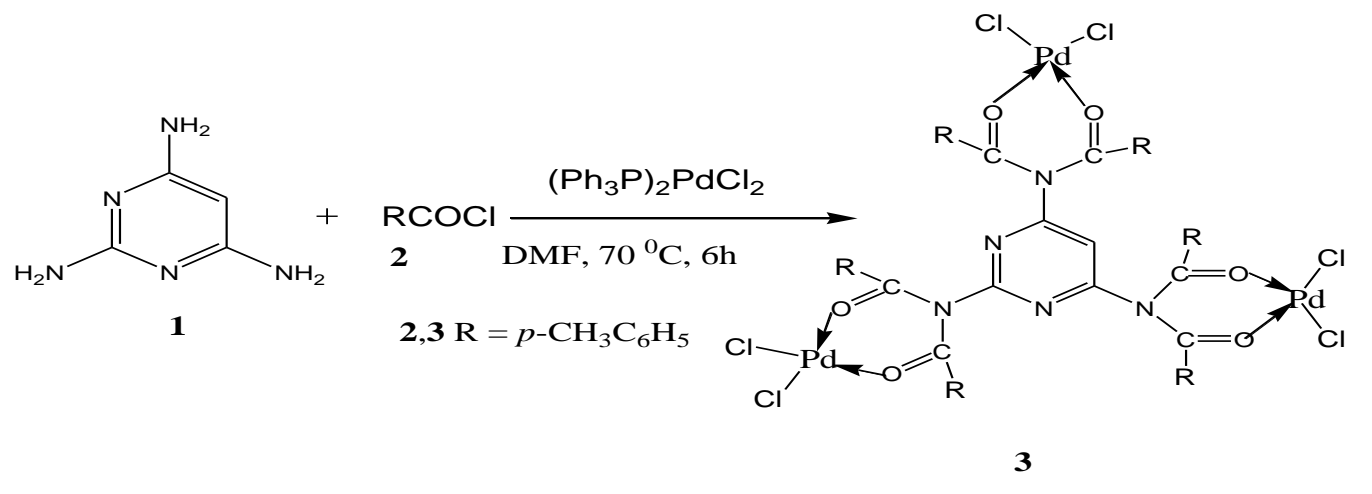

Scheme 1 
Table 1:-Optimization for Preparation of Metallodendrimer 3

\begin{tabular}{|c|c|c|c|c|c|c|}
\hline Entry & $\begin{array}{c}\mathbf{1} \\
(\mathbf{m m o l})\end{array}$ & $\begin{array}{c}\mathbf{2} \\
(\mathbf{m m o l})\end{array}$ & $\begin{array}{c}\text { Pd complex } \\
(\mathbf{m o l})\end{array}$ & $\begin{array}{c}\text { Solvent } \\
(\mathbf{m L})\end{array}$ & $\begin{array}{c}\text { Time } \\
(\mathbf{h})\end{array}$ & $\begin{array}{c}\mathbf{4} \\
(\boldsymbol{\%})\end{array}$ \\
\hline 1 & 1.59 & 9.54 & $\left(\mathrm{Ph}_{3} \mathrm{P}\right)_{2} \mathrm{PdCl}_{2}(10)$ & $\mathrm{DMF}(10)$ & 6 & 90 \\
\hline 2 & 1.59 & 9.54 & $\mathrm{PdCl}_{2}(10)$ & $\mathrm{DMF}(10)$ & 6 & 60 \\
\hline 3 & 1.59 & 9.54 & $\left(\mathrm{Ph}_{3} \mathrm{P}\right)_{2} \mathrm{PdCl}_{2}(10)$ & $\mathrm{THF}(10)$ & 6 & 55 \\
\hline 4 & 1.59 & 9.54 & $\left(\mathrm{Ph}_{3} \mathrm{P}\right)_{2} \mathrm{PdCl}_{2}(10)$ & $\mathrm{DMSO}(10)$ & 6 & 85 \\
\hline 5 & 1.59 & 9.54 & $\left(\mathrm{Ph}_{3} \mathrm{P}\right)_{2} \mathrm{PdCl}_{2}(20)$ & $\mathrm{DMSO}(10)$ & 6 & 70 \\
\hline
\end{tabular}

The assignments of IR spectral bands most useful in establishing the structural identity of metal complexes. The strong IR peak of $\mathbf{3}$ confirmed the presence of required groups of the compound. The appearance of the signal in the range of $3000-3100 \mathrm{~cm}^{-1}$ and $1680-1760 \mathrm{~cm}^{-1}$ represented the $\mathrm{C}-\mathrm{H}, \mathrm{C}=\mathrm{O}$ group respectively whereas a strong absorption band at $1580-1620 \mathrm{~cm}^{-1}$ displayed $\mathrm{C}=\mathrm{N}$. The peak at $1300-1360$, and $1250-1335 \mathrm{~cm}^{-1} \mathrm{confirmed} \mathrm{the}^{-1}$ presence of $\mathrm{C}=\mathrm{C}$ and $\mathrm{C}-\mathrm{N}$ group respectively. $\mathrm{C}-\mathrm{Cl}$ stretching absorption was observed at $761.8 \mathrm{~cm}^{-1}$. Here it's far remarkable that there's no band for $\mathrm{N}-\mathrm{H}$ in the place approximately $3400-3250 \mathrm{~cm}-1$ which turned into indicated that $1^{\circ}$ amino group of triaminodiazine is transformed into $3^{\circ}$ amido group. In ${ }^{\mathrm{I}} \mathrm{H} \mathrm{NMR}$ and ${ }^{13} \mathrm{C} \mathrm{NMR}$ spectra confirmed the preferred compound 3. Because of the formation of $\mathrm{Pd}-\mathrm{O}$ coordinated bond, small adjustments within the aromatic area in comparison to starting materials indicated that metallic complexation has been achieved. There's no ${ }^{1} \mathrm{H}$ NMR peak for $\mathrm{NH}$ or $\mathrm{NH}_{2}$ group, which confirmed the shape of compound 3 . The self-assembly procedure of the compound 3 was investigated with $\mathrm{Pd}$ (II) as the central metal ions, and this led to a well-designated four coordinated complex that was confirmed through MALDI-TOF MS ( Figures S 1- S 6 in the Supporting Information).

The images of the compound (3) were taken in a Scanning Electron Microscope (SEM) at an accelerating voltage of $10 \mathrm{KV}$ with magnifications ranging from $100 \mu \mathrm{m}-500 \mathrm{~nm}$.SEM images of the compound 3 revealed that the formation of high component ratio randomly disbursed, entangled nanofibers. The length of the fibers is numerous $\mu \mathrm{M}$. Coordination between the ligand and Pd (II) fashioned "branches of a tree without leaves and cylindrical fiberlike shape for compound 3 (Fig 1). Every chain stacked with neighboring chain by way of $\pi$ - $\pi$ stacking interaction and shaped fibril morphology. The fibers are stabilized with the aid of $\pi$-stacking of the aromatic core of the ligands.
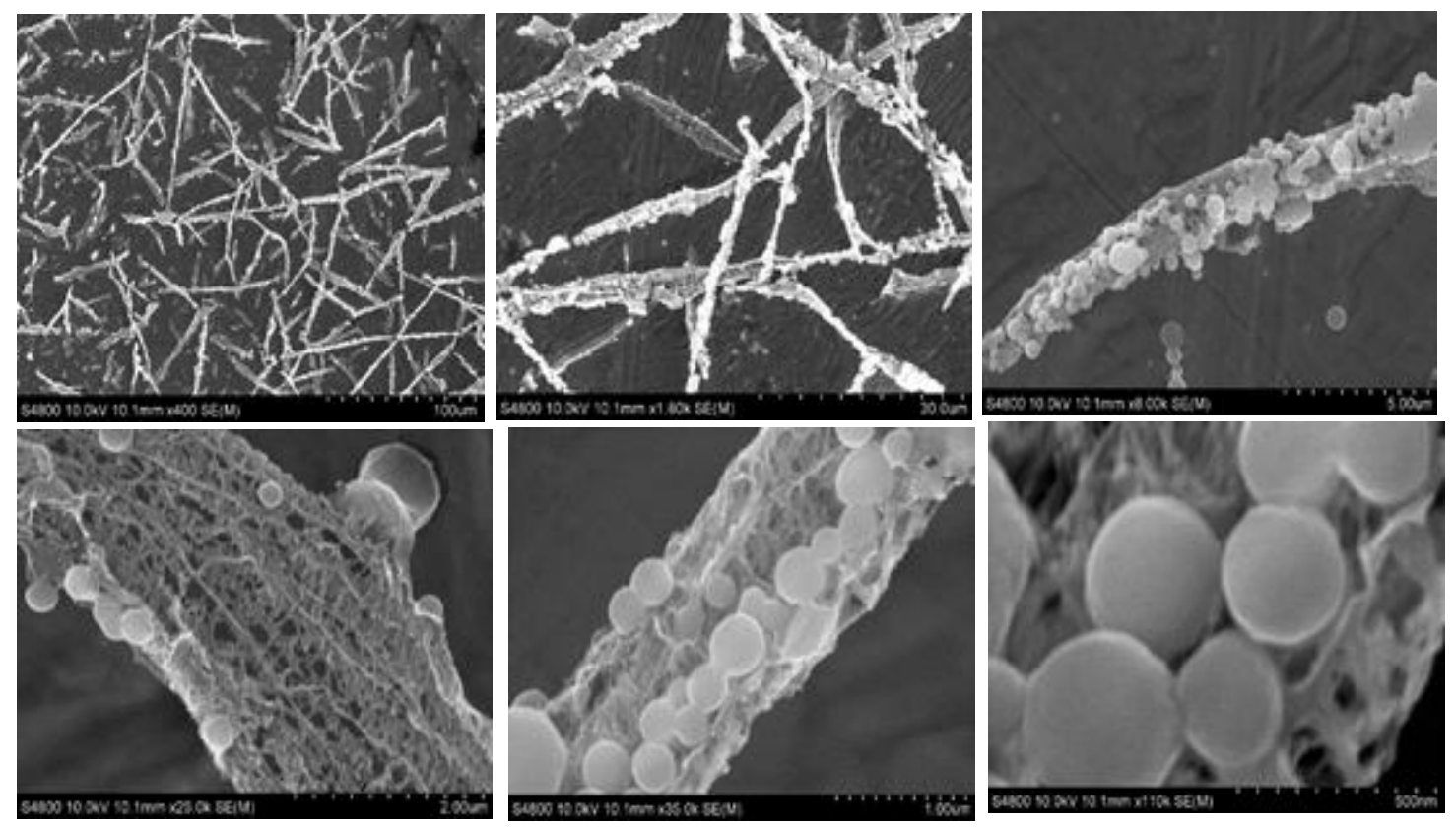

Figure 1:-SEM images of the compound 3 


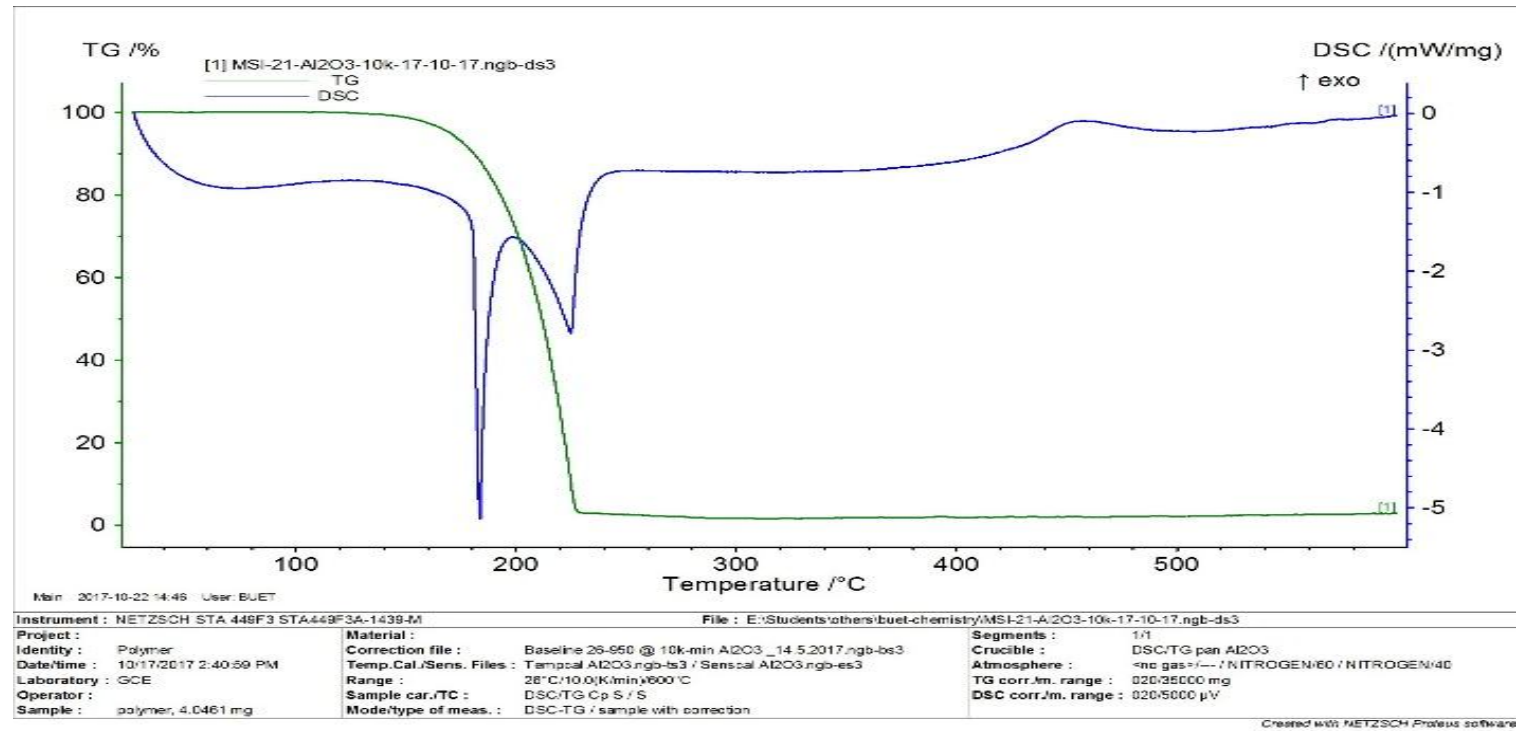

Figure 2:-TG and DSC curves of the compound 3

Metal detection or analysis of metallodendrimer has been accomplished through employing the energy Dispersive X-ray (EDX) method. From EDX evaluation, the existence of Palladium turned into properly detected and it was $4.10 \%$ of weight and $0.56 \%$ of atomic of the compound and chlorine was $0.82 \%$ of weight and $0.33 \%$ of atomic of the compound 3. So it is able to be stated that palladium metal was present as palladium chloride in our desired synthesized compound and the reaction was effective for the preparation of the required metallodendrimer 3 .

The thermal properties of the metallodendrimers, 3 was studied by TG and DSC at temperatures of $26{ }^{\circ} \mathrm{C}$ to $600^{\circ} \mathrm{C}$ under a nitrogen atmosphere (figure 2). The content of a particular component of metallodendrimer changes with its composition and structure and determined on the basis of the weight reduction of these components in the thermogravimetric graph. It was found from TG curve that actual weight reduction of the compound 3 from $185^{\circ} \mathrm{C}$ to $230{ }^{\circ} \mathrm{C}$. The thermogram of TG for compound 3 showed two different stages of decomposition at $185^{\circ} \mathrm{C}$ to $230{ }^{\circ} \mathrm{C}$, and the DSC values of the compound were nearly the same as that of TG values of the compound. In the DSC curve of 3 display the sharp endothermic curve above $185^{\circ} \mathrm{C}$ representing the melting points. The primary decomposition stage confirmed $86.99 \%$ weight loss of compound 3 .

We have reported new homogeneous palladium containing metallodendrimer (3) based on diazine catalyst which is an air-stable and very much effective catalyst for the Heck, Sonoghasira coupling reactions. In order to evaluate the activities of our catalytic system, the reaction between iodobenzene and phenylacetylene was initially selected for the Sonoghasira coupling reaction in the presence of a catalytic amount of the Pdmetallodendrimer 3 as a homogeneous catalyst (Scheme 2, Table 2). The catalytic systems revealed different reactivity depending not only on the palladium precursor but also on the nature of the base and the solvent and temperature.

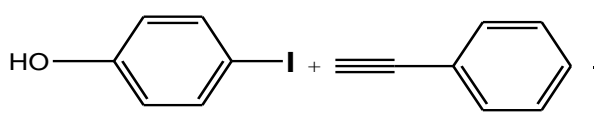

Pd-metallodendrimer $1.5 \mathrm{~mol} \%$, CuI $1 \mathrm{~mol} \%$

Base, solvent,

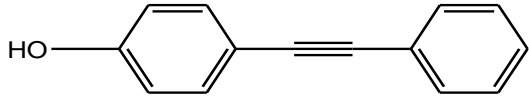

$70{ }^{\circ} \mathrm{C}$, Time

\section{Scheme 2}

Table 2:-Optimization of the Pd-metallodendrimer 3 catalyzed Sonogashira reaction between 4-iodophenol and phenylacetylene

\begin{tabular}{|l|l|l|l|l|l|l|}
\hline Entry & Base & solvent & Time & $\begin{array}{l}\text { Co-Catalyst } \\
\text { CuI mol\% }\end{array}$ & $\begin{array}{l}\text { Catalyst (3) } \\
\text { mol\% } \%\end{array}$ & Yield\% \\
\hline 1 & $\mathrm{KO}^{t} \mathrm{Bu}$ & $\mathrm{CH}_{3} \mathrm{CN}$ & 3 & - & 1.0 & 63 \\
\hline 2 & $\mathrm{Na}_{2} \mathrm{CO}_{3}$ & $\mathrm{CH}_{3} \mathrm{CN}$ & 3 & - & 1.5 & 70 \\
\hline
\end{tabular}




\begin{tabular}{|l|l|l|l|l|l|l|}
\hline 3 & $\mathrm{~K}_{2} \mathrm{CO}_{3}$ & DMF & 3 & - & 1.0 & 75 \\
\hline 4 & $\mathrm{Et}_{3} \mathrm{~N}$ & DMF & 2 & 1.0 & 1.5 & 90 \\
\hline 5 & $\mathrm{~K}_{2} \mathrm{CO}_{3}$ & $\mathrm{CH}_{3} \mathrm{OH}$ & 24 & 2.0 & - & - \\
\hline
\end{tabular}

t-BuOK, $\mathrm{Na}_{2} \mathrm{CO}_{3}$, and $\mathrm{K}_{2} \mathrm{CO}_{3}$ with $\mathrm{CH}_{3} \mathrm{CN}$ or DMF as the solvent were appropriate bases to complete the Sonogashira coupling without using $\mathrm{CuI}$ at $70{ }^{\circ} \mathrm{C}$ for $3 \mathrm{~h}$ with a yield higher than $60 \%$ (Table 2, entries 1-3). Copper salts are used as co-catalysts within the Sonogashira reaction, even though it makes the Sonogashira method air sensitive. Notwithstanding this drawback, copper salts in the presence of a base have been used notably for the formation of $\mathrm{Cu}$-alkynyl species that transmetallate to palladium within the catalytic cycle. Due to investigate the effect of $\mathrm{CuI}$ as a catalyst, a blank experiment was performed in the absence of a palladium-metallodendrimer $\mathbf{3}$ catalyst revealed that no reaction happened even within the presence of $\mathrm{CuI}(2 \mathrm{~mol} \%)$ at 24 hour ( Table 2, entry 5). In the presence of $\mathrm{Et}_{3} \mathrm{~N}, \mathrm{DMF}$, Pd-metallodendrimer $3(1.5 \mathrm{~mol} \%)$ as well as $\mathrm{CuI}(1.0 \mathrm{~mol} \%)$, the reaction was completed within two hours without any deleterious effects at the conversions with $90 \%$ yield ( Table 2, entry 4).

Therefore, the optimized reaction condition was found with $90 \%$ yield when $1.5 \mathrm{~mol} \%$ of Pdmetallodendrimer 3 as a catalyst, $1.0 \mathrm{~mol} \% \mathrm{CuI}$ as a co-catalyst, $\mathrm{Et}_{3} \mathrm{~N}$, and DMF were used under the nitrogen atmosphere at $70{ }^{\circ} \mathrm{C}$ at 2 hour (Table 2, Entry 4). After optimization, we achieved the catalytic activities with more electron-donating or greater sterically hindered aryl halide substrates. Good to remarkable conversions were acquired with the greater electron-donating or extra sterically hindered methyl and methoxy-substituted aryl halide substrates under the chosen reaction catalyzed by compound 3 after $2 \mathrm{~h}$ (Scheme 3, Table 3, Entries 1-6)

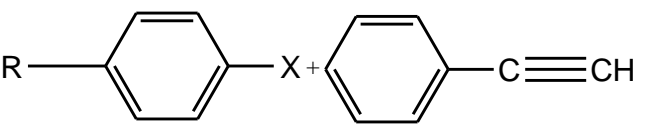

\section{$1.5 \mathrm{~mol} \%$ Pd-}

metallodendrimer $3, \mathrm{CuI}$

$$
1.0 \mathrm{~mol} \%
$$

DMF, $70{ }^{\circ} \mathrm{C}$

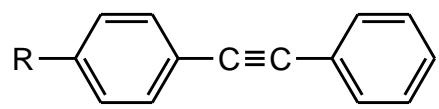

$\mathrm{Et}_{3} \mathrm{~N}, 2$ hour

4-12

13

Scheme 3

14-16

Table 3:-Sonogashira coupling reaction of different aryl chlorides with phenylacetylene catalyzed by Pdmetallodendrimer 3.

\begin{tabular}{|l|l|l|l|l|}
\hline Entry & $\mathrm{R}$ & $\mathrm{X}$ & product & Yield\% \\
\hline 1 & $4, \mathrm{OH}$ & $4, \mathrm{I}$ & 14 & 90 \\
\hline 2 & $5, \mathrm{OH}$ & $5, \mathrm{Br}$ & 14 & 80 \\
\hline 3 & $6, \mathrm{CH}_{3}$ & $6, \mathrm{I}$ & 15 & 94 \\
\hline 4 & $7, \mathrm{CH}_{3}$ & $7, \mathrm{Br}$ & 15 & 81 \\
\hline 5 & $8, \mathrm{OCH}_{3}$ & $8, \mathrm{I}$ & 16 & 95 \\
\hline 6 & $9, \mathrm{OCH}_{3}$ & $9, \mathrm{Br}$ & 16 & 80 \\
\hline
\end{tabular}

\section{Reaction conditions:}

Aryl halide $(1 \mathrm{mmol})$, phenylacetylene $(1.2 \mathrm{mmol})$, catalyst $(1.5 \mathrm{~mol} \%)$, base $(1.2 \mathrm{mmol})$, solvent $(5 \mathrm{~mL}), 70{ }^{\circ} \mathrm{C}, 2 \mathrm{~h}$, under nitrogen atmosphere, Yield\% was calculated based on aryl halide.

Similarly, due to optimization the Heck reaction conditions, a series of reactions under various combinations of bases, solvents, and temperatures, using Pd-metallodendrimer 3 as a catalyst, was pursued. Iodobenzene and styrene were selected as the typical substrates in this coupling reaction and the outcomes have been presented in Scheme 4 (Table 4).

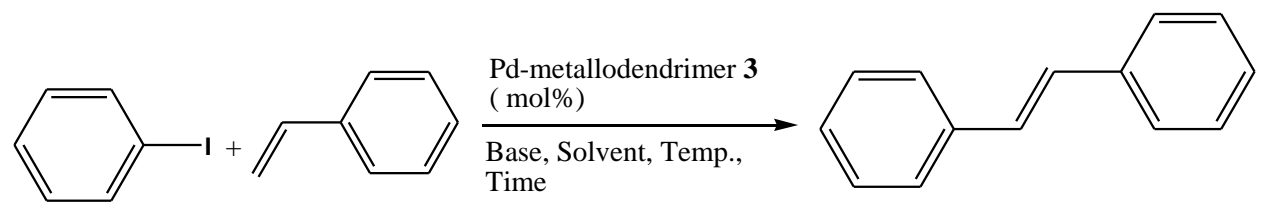

Scheme 4 
Table 4:-Optimization of the Pd-metallodendrimer 3 catalyzed Heck reaction between 4-iodobenzene and styrene

\begin{tabular}{|l|l|l|l|l|l|l|}
\hline Entry & Time $(\mathrm{h})$ & Base & Temp $\left({ }^{\circ} \mathrm{c}\right)$ & solvent & $\begin{array}{l}\text { Catalyst, 3 } \\
(\mathrm{mol} \%)\end{array}$ & Yield (\%) \\
\hline 1 & 24 & $\mathrm{NaOH}$ & $\mathrm{RT}$ & $\mathrm{CH}_{3} \mathrm{CN}$ & 1.5 & - \\
\hline 2 & 24 & $\mathrm{Na}_{2} \mathrm{CO}_{3}$ & $\mathrm{RT}$ & $\mathrm{DMSO}$ & 2.0 & - \\
\hline 3 & 20 & $\mathrm{Et}_{3} \mathrm{~N}$ & 60 & $\mathrm{DMF}$ & 2.0 & 50 \\
\hline 4 & 24 & $\mathrm{~K}_{2} \mathrm{CO}_{3}$ & 85 & $\mathrm{CH}_{3} \mathrm{OH}$ & 1.5 & 60 \\
\hline 5 & 26 & $\mathrm{KO}^{\mathrm{t}} \mathrm{Bu}$ & 85 & $\mathrm{CH}_{3} \mathrm{C}_{6} \mathrm{H}_{5}$ & 1.5 & 70 \\
\hline 6 & 24 & $\mathrm{~K}_{2} \mathrm{CO}_{3}$ & 85 & $\mathrm{DMF}$ & 1.5 & 75 \\
\hline 7 & 24 & $\mathrm{Et}_{3} \mathrm{~N}$ & 85 & $\mathrm{DMF}$ & 1.5 & 90 \\
\hline
\end{tabular}

Reaction conditions: Iodobenzene $(1 \mathrm{mmol})$, styrene $(1.2 \mathrm{mmol})$, base $(1.2 \mathrm{mmol}), 24$ hour, Temp. $85{ }^{\circ} \mathrm{C}$, Yields $\%$ was calculated on the basis of iodobenzene.

The coupled product was not found, when the coupling reaction was started with using 1.5 mol \% Pdmetallodendrimer 3 as a catalyst, with styrene $(1.2 \mathrm{mmol})$, and Iodobenzene $(1 \mathrm{mmol})$ in $\mathrm{CH}_{3} \mathrm{CN}$ or DMSO $(5 \mathrm{~mL})$, and at room temperature in the presence of $\mathrm{NaOH}$ or $\mathrm{Na}_{2} \mathrm{CO}_{3}$ (1.2 equivalent) at $24 \mathrm{~h}$ (table 4, entries 1-2). Interestingly, the reaction confirmed the progress of 50\% yield with 2 mol\% of compound 3 in the presence of $\mathrm{Et}_{3} \mathrm{~N}$ and DMF at $60{ }^{\circ} \mathrm{C}$ at $20 \mathrm{~h}$ (Table 4, entry 3). Moreover, using other bases including $\mathrm{K}_{2} \mathrm{CO}, \mathrm{KO}^{\mathrm{t}} \mathrm{Bu}$ and in the presence of the solvents, methanol, toluene or DMF at $85{ }^{\circ} \mathrm{C}$, the coupling products were found above $60 \%$ yield (table 4, entries 4-6). The best result was found when $1.5 \mathrm{~mol} \%$ of the catalytic system (3) and $\mathrm{Et}_{3} \mathrm{~N}$, as a base, and solvent DMF were used under the nitrogen atmosphere at $85{ }^{\circ} \mathrm{C}$ at $24 \mathrm{~h}$ for Heck coupling reaction (Table 4, entry 7).

Table 5:-Heck coupling reaction of different aryl chlorides with different olefins catalyzed by Pd-metallodendrimer 3.

\begin{tabular}{|l|l|l|l|}
\hline Entry & Aryl halides & Yield\% \\
\hline 1 & & &
\end{tabular}

Yield\% was calculated based on aryl halide.

A wide variety of olefins and diversely substituted aryl halides were selected for cross-coupling to produce the corresponding 1, 2-disubstituted olefins. The results have been summarized in table 5. Though aryl bromides and aryl iodides performed nicely (Table 5, entries 1-3) under these optimized Heck reaction conditions. However, while compared to the iodo analogues with bromo analogues, a reduced reactivity was discovered in the case of the corresponding bromo derivatives and was found less yield $\%$ of the product. 
Above all coupling products for Sonogasira and Heck reaction were analyzed by spectroscopic methods and compared with authentic spectra. (Figures S 07-S 12 and S 13-S 21 in the supporting information)

\section{Conclusion:-}

In summary, A novel palladium containing metallodendrimer 3 was prepared by the coordination reaction of 2,4,6-triaminopyrimidine (1) with 4-methyl benzoyl chloride (2). The complexation was clearly observed in ${ }^{1} \mathrm{H}$ NMR, ${ }^{13} \mathrm{C}$ NMR, and mass spectra. SEM images of 3 revealed branches of the tree without leafs or cylindrical fiber. Thermal stability of the metallodendrimer 3 was determined by TG and DSC analysis which showed good thermal stability of the compound and can be stored in the white solid crystalline state for a long time at ambient temperature without decomposition. The homogeneous catalyst system showed several advantages including low catalyst loading, substrate tolerance, very good yields, green solvents, short reaction times and very simple procedure for synthesizing Heck and Sonogashira coupling reaction products that are biologically important in the various field. These outcomes signify a noteworthy development in the field of C-C bond formation reactions.

\section{Acknowledgement:-}

We would like to express our deepest gratitude to Bangladesh University of Engineering and Technology (BUET), Dhaka, Bangladesh and Ministry of Science \& Technology, Dhaka, Bangladesh for giving the financial support to carry out our research work.

\section{Conflicts of Interest}

The authors declare no conflicts of interest

\section{Graphical abstract}

\section{A facile synthesis of Palladium containing Metallodendrimer based on Diazine and its application as a catalyst}

Md. Sayedul Islam ${ }^{a}$ and Md. Wahab Khan* ${ }^{a}$

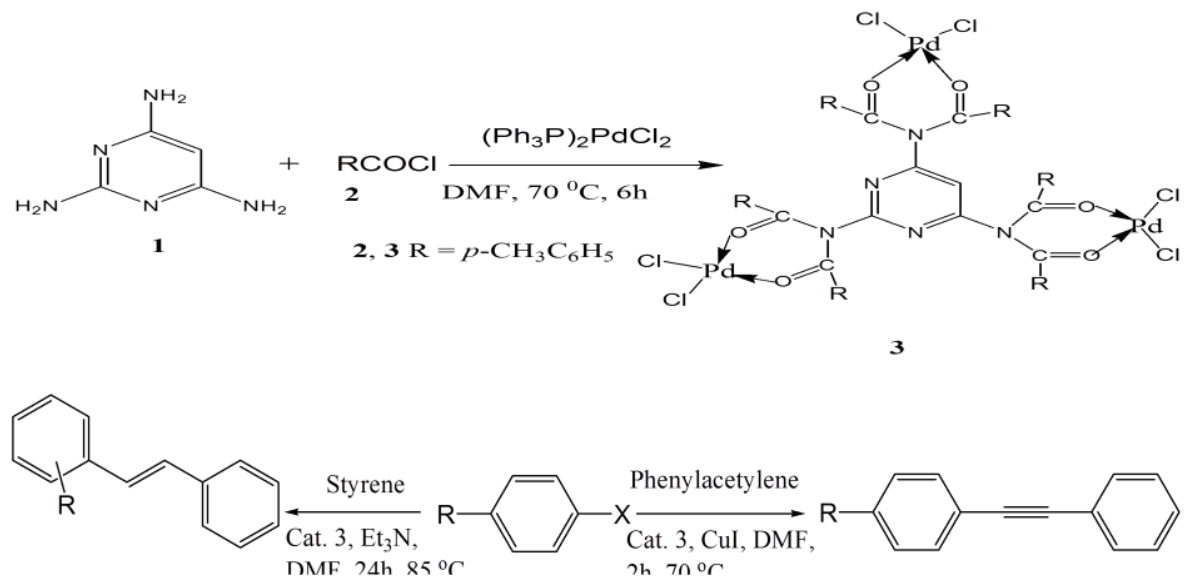

\section{References:-}

1. Kostas, I. D., Andreadaki, F. J., Medlycott, E. A., Hanan, G. S. and Monflier, E. (2009): Synthesis of a halomethylphenylene periphery-functionalized triazine-based dendritic molecule with a 3, 3'-dimethyl-biphenyl linker using tris (halo-methylphenylene) triazines as building blocks. Tetrahedron Letters, 50(16): 1851-1854.

2. Kaanumalle, L. S., Ramesh, R., Murthy Maddipatla, V. S. N., Nithyanandhan, J., Jayaraman, N. and Ramamurthy, V. (2005): Dendrimers as photochemical reaction media. Photochemical behavior of 
unimolecular and bimolecular reactions in water-soluble dendrimers. The Journal of organic chemistry, 70(13): 5062-5069

3. Tomalia, D. A., Naylor, A. M. and Goddard III, W. A. (1990): Starburst dendrimers: molecular level control of size, shape, surface chemistry, topology, and flexibility from atoms to macroscopic matter. Angewandte Chemie International Edition in English, 29(2): 138-175.

4. Frechet, J. M. (1994): Functional polymers and dendrimers: reactivity, molecular architecture, and interfacial energy. Science, 263(5154): 1710-1715.

5. Liu, M., Kono, K. and Fréchet, J. M. (2000): Water-soluble dendritic unimolecular micelles:: Their potential as drug delivery agents. Journal of Controlled Release, 65(1-2): 121-131.

6. Newkome, G. R., Yao, Z., Baker, G. R., \& Gupta, V. K. Micelles. Part 1. Cascade molecules: a new approach to micelles. A [27]-arborol. (1985): The Journal of Organic Chemistry, 50(11): 2003-2004.

7. Stevelmans, S., Van Hest, J. C. M., Jansen, J. F. G. A., Van Boxtel, D. A. F. J., De Brabander-van den Berg, E. M. M. and Meijer, E. W. (1996): Synthesis, Characterization, and Guest- Host Properties of Inverted Unimolecular Dendritic Micelles. Journal of the American Chemical Society 118(31): 7398-7399.

8. Yang, H. and Kao, W. J. (2006): Dendrimers for pharmaceutical and biomedical applications. Journal of biomaterials science, polymer edition, 17(1-2): 3-19.

9. Zhao, M., Sun, L. and Crooks, R. M. (1998): Preparation of Cu nanoclusters within dendrimer templates. Journal of the American Chemical Society, 120(19): 4877-4878.

10. Balogh, L. and Tomalia, D. A. (1998): Poly (amidoamine) dendrimer-templated nanocomposites. 1. Synthesis of zerovalent copper nanoclusters. Journal of the American Chemical Society, 120(29): 7355-7356.

11. Gröhn, F., Bauer, B. J., Akpalu, Y. A., Jackson, C. L. and Amis, E. J. (2000): Dendrimer templates for the formation of gold nanoclusters. Macromolecules, 33(16): 6042-6050.

12. Scott, R. W., Ye, H., Henriquez, R. R. and Crooks, R. M. (2003): Synthesis, characterization, and stability of dendrimer-encapsulated palladium nanoparticles. Chemistry of Materials, 15(20): 3873-3878.

13. Gu, Y., Xie, H., Gao, J., Liu, D., Williams, C. T., Murphy, C. J. and Ploehn, H. J. (2005): AFM characterization of dendrimer-stabilized platinum nanoparticles. Langmuir, 21(7): 3122-3131.

14. Peng, Z., Zhang, J., Sun, X., Yang, J. and Diao, J. (2009): The thermolysis behavior of Ag/PAMAMs nanocomposites. Colloid and Polymer Science, 287(5): 609-614.

15. Atwater, J. E., Akse, J. R. and Holtsnider, J. T. (2008): Cobalt-poly (amido amine) super paramagnetic nanocomposites. Materials letters, 62(17-18): 3131-3134.

16. Kotta, K. K. (2006): Design, Synthesis, and Characterization of $[1 \rightarrow 3] ;[1 \rightarrow(2+1 \mathrm{Me})] ;[1 \rightarrow(2+1)] \mathrm{C}-\mathrm{Branched}$ Dendrons and Dendritic Architectures (Doctoral dissertation, University of Akron).

17. Gu, Y., Wu, G., Hu, X. F., Chen, D. A., Hansen, T., zur Loye, H. C. and Ploehn, H. J. (2010): PAMAMstabilized Pt-Ru nanoparticles for methanol electro-oxidation. Journal of Power Sources, 195(2): 425-434.

18. He, G., Guo, L. and Ma, L. F. (2006): Synthesis of novel dendrimers containing amino acids and peptides. Chinese Chemical Letters, 17(3): 289-292.

19. Franc, G. and Kakkar, A. K. (2009): Diels-Alder "click" chemistry in designing dendritic macromolecules. Chemistry-A European Journal, 15(23): 5630-5639.

20. Antoni, P., Nyström, D., Hawker, C. J., Hult, A. and Malkoch, M.(2007): A chemoselective approach for the accelerated synthesis of well-defined dendritic architectures. Chemical communications, 22: 2249-2251.

21. Carlmark, A., Hawker, C., Hult, A. and Malkoch, M. (2009): New methodologies in the construction of dendritic materials. Chemical Society Reviews, 38(2): 352-362.

22. Franc, G., and Kakkar, A. (2008): Dendrimer design using CuI-catalyzed alkyne-azide "click-chemistry". Chemical Communications, 42: 5267-5276.

23. Civicos, J. F., Alonso, D. A. and Najera, C. (2013): Microwave- Promoted Copper- Free SonogashiraHagihara Couplings of Aryl Imidazolylsulfonates in Water. Advanced Synthesis \& Catalysis, 355(1): $203-208$.

24. Boubakri, L., Yasar, S., Dorcet, V., Roisnel, T., Bruneau, C., Hamdi, N. and Ozdemir, I. (2017): Synthesis and catalytic applications of palladium N-heterocyclic carbene complexes as efficient pre-catalysts for SuzukiMiyaura and Sonogashira coupling reactions. New Journal of Chemistry, 41(12): 5105-5113.

25. Sonogashira, K., Tohda, Y. and Hagihara, N. (1975): A convenient synthesis of acetylenes: catalytic substitutions of acetylenic hydrogen with bromoalkenes, iodoarenes and bromopyridines. Tetrahedron letters, 16(50): 4467-4470.

26. Biffis, A., Centomo, P., Del Zotto, A., \& Zecca, M. (2018): Pd metal catalysts for cross-couplings and related reactions in the 21st century: A critical review. Chemical reviews, 118(4), 2249-2295.

27. Fleckenstein, C. A., \& Plenio, H. (2010): Sterically demanding trialkylphosphines for palladium-catalyzed cross coupling reactions - alternatives to PtBu3. Chemical Society Reviews, 39(2), 694-711. 
28. Plenio, H. (2008): Catalysts for the Sonogashira Coupling-The Crownless Again Shall Be King. Angewandte Chemie International Edition, 47(37): 6954-6956.

29. Doucet, H. and Hierso, J. C. (2007): Palladium-based catalytic systems for the synthesis of conjugated enynes by Sonogashira reactions and related alkynylations. Angewandte Chemie International Edition, 46(6): 834-871.

30. Prabhu, R. N., \& Pal, S. (2015): Copper-free Sonogashira reactions catalyzed by a palladium (II) complex bearing pyrenealdehyde thiosemicarbazonate under ambient conditions. Tetrahedron letters, 56(37): 5252-5256.

31. Boyarskii, V. P. (2017): Sonogashira reaction catalyzed by palladium isocyanide complex modified in situ. Russian Journal of General Chemistry, 87(8): 1663-1666.

32. Zhang, Z., \& Wang, Z. (2006): Diatomite-supported Pd nanoparticles: an efficient catalyst for Heck and Suzuki reactions. The Journal of organic chemistry, 71(19): 7485-7487. 